\title{
Performance Analysis of Organic Rankine Cycle Integrated with a Parabolic Through Solar Collector
}

\author{
Milad Ashouri ${ }^{1,}$ Mohammad Hossein Ahmadi $^{1 *}$, Michel Feidt ${ }^{2}$ \\ ${ }^{1}$ Department of Renewable Energies, Faculty of New Science and Technologies, University of \\ Tehran, Tehran, Iran \\ ${ }^{2}$ Laboratoire d' Energétique et de Mécanique Théorique et Appliquée, ENSEM, 2, avenue de laForêt \\ de Haye 6060454518 Vandoeuvre, France
}

E-Mails: ashouri.milad@ut.ac.ir; mohammadhosein.ahmadi@gmail.com; michel.feidt@univlorraine.fr

* Department of Renewable Energies, Faculty of New Science and Technologies, University of Tehran, Tehran, Iran; Tel.: +989122866205;

Received: 20 June 2014 / Accepted: 31 October 2014 / Published: 3 November 2014

\begin{abstract}
Recently, distributed power generation systems especially with renewable sources have shown a promising result all over the world and have been a technical solution to demand growth for electricity. Among these, solar thermal power plants show a trustworthy source for electricity generation especially for rural areas where small scale solar plants are used. Organic Rankine Cycle (ORC) is a suitable means for electricity generation from low grade heat and has shown a good compatibility with parabolic trough solar collectors (PTC). Here, a PTC integrated with an ORC cycle is being investigated for small scale electricity generation near Tehran. The system includes a solar field, a storage tank, and a small scale ORC engine. Performance evaluation has been done by means of commercial software Thermoflex19. Analysis to find the optimal design point turbine pressure and evaporator temperature for obtaining the best performance shows the effect of turbine inlet pressure and evaporator temperature on various cycle characteristics such as net output work, efficiency, solar heat input, oil temperature, collector efficiency and characteristics of heat exchangers such as pinch point and current UA. A comparison of different working fluids is presented. Results show that Benzene has the best performance
\end{abstract}


among fluids butane, n-pentane, Iso-pentane, R123 and R245fa for the system conditions described.

Keywords: Organic Rankine Cycle; turbine pressure; evaporator temperature; efficiency; net output work

\section{Introduction}

Organic Rankine cycles have received much attention during last decade. This cycle obeys the fundamental rules of conventional Rankine cycles working with water in common plants but has some advantages over water Rankine cycle which made it popular. First this cycle can work under low temperatures and pressures in comparison to conventional Rankine cycle and shows a better performance than water especially from low grade heat sources because its working fluids include a variety of hydrocarbons and refrigerants and according to the range of accessible heat source temperatures and pressures, different outputs can be derived by using suitable working fluids, second, it can work without feed-water heaters and multi-stage turbines which makes it simple to use. Among these, solar parabolic trough collectors are a huge source of thermal energy but with a low grade heat which makes it only suitable for some kilowatts to few megawatts electricity generation, also it shows a reliable means for electricity generation especially in rural areas or near factories to generate their electricity consumption without the need for connection to grid which may be expensive. Disadvantages of solar ORCs are relatively high costs [1] and low thermal efficiency (10 to 25 percent according to working fluids and working condition) mainly because of low HTF (Heat transfer fluid) temperature in solar collectors. As mentioned before, the organic fluids used in ORC cycles are divided into hydrocarbons and refrigerants, some of them are dry fluids which mean they have a positive slope T-S diagram in the saturation vapor region. This makes it possible for some organic fluids to work properly without superheating to a great extent and cause no damage to turbine. As shown in this study, a comparison of different dry organic fluids with and without superheating and recuperation has been done to show the variance in cycle efficiency and performance of the system which helps us to make a decision to choose the system conditions according to our needs. ORC cycle has been put under investigation by many authors, Wang and et al. presented a detailed analysis of organic Rankine cycle coupled with solar collector with a thermal storage system during a whole day [2]. MCMAHAN designed and optimized a solar-thermal ORC [3]. Quoilin and et al. presented an optimization and sizing procedure of heat exchangers in a small scale solar driven ORC by pinch and pressure drop and optimized it by turbine input pressure and evaporator temperature [4]. Ferrara $\mathrm{F}$ and et al. compared different organic fluids and in a $20 \mathrm{KWe}$ solar plant [1] and chose Acetone as the best organic fluid choice with supercritical pressure.

In this study a small scale organic Rankine cycle driven by a parabolic trough solar collector was simulated using Thermoflow software [5] with various organic fluids and different schematics, results were compared and the effect of key parameters in the cycle such as turbine inlet pressure and turbine inlet temperature, were investigated, also optimum pressures were selected in each case. 


\section{Thermodynamic Analysis}

Schematic of ORCS (Solar Organic Rankine cycle) are presented in figure 1. Also the process in T$S$ diagram is shown for benzene in figure 2.

Figure1: Schematic diagram of a solar organic Rankine cycle with Super heater and Recuperator.

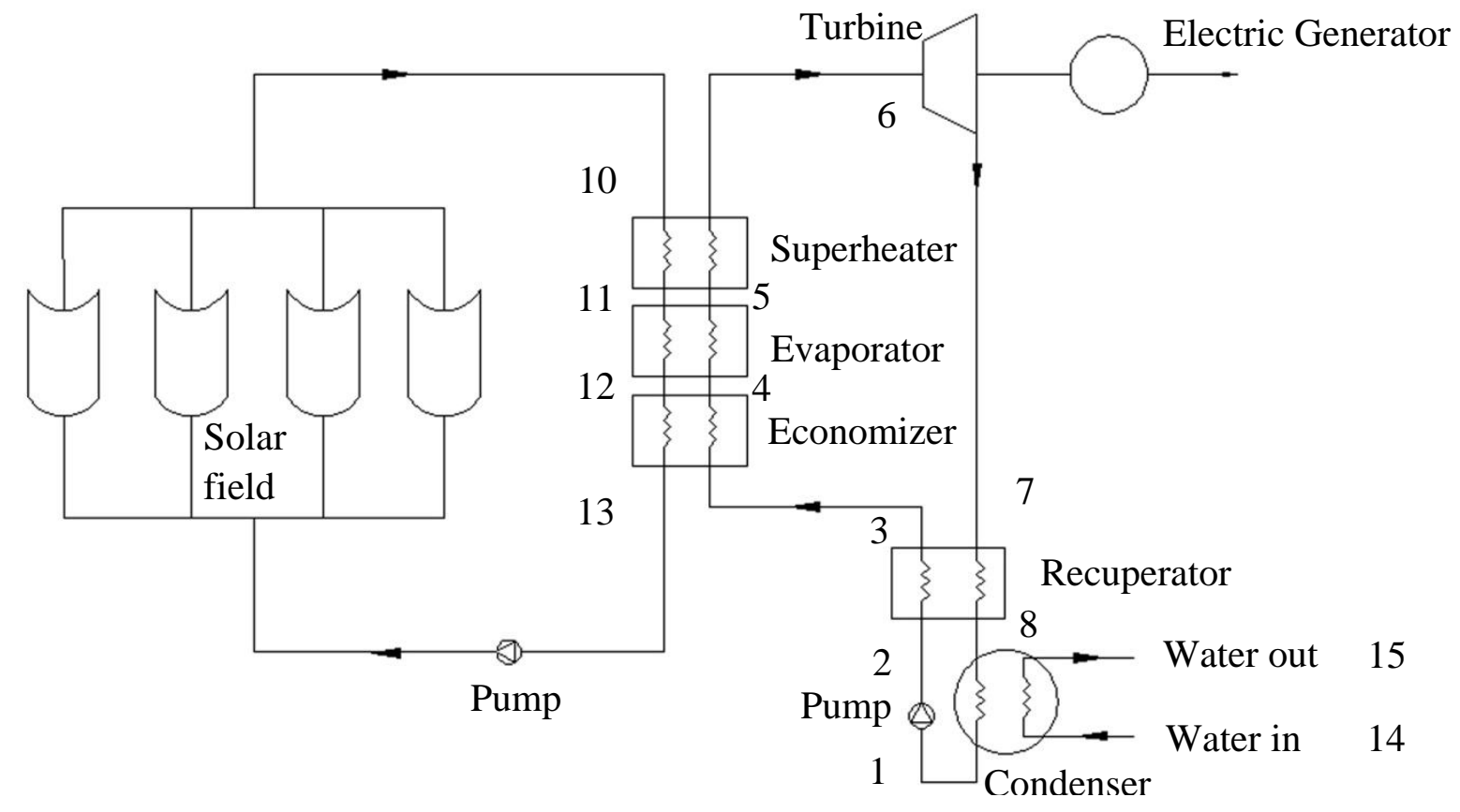

Figure 2. T-S diagram for the ORC process (Benzene)

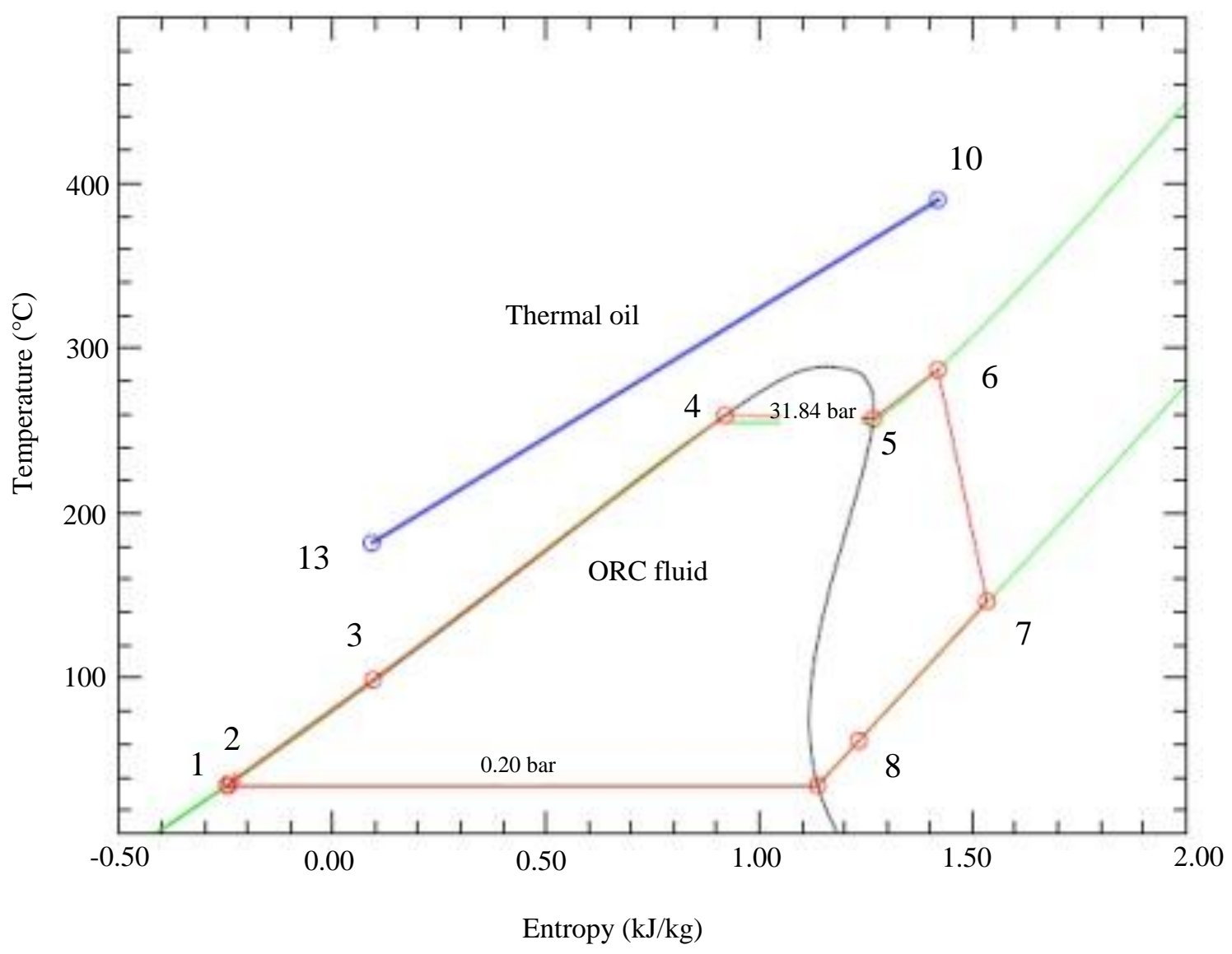


ORC fluid is pumped through economizer, the first heat exchanger in the solar field, and is heated to its saturation temperature then it enters to evaporator which two phase mixture is transformed to pure vapor in a constant temperature, the third heat exchanger superheats the fluid and raise the temperature in a constant pressure. Vapor in state 6 enters the turbine and deliver the power, because of high energy content of vapor in state 7 we can reuse its energy by entering the fluid in a heat exchanger called Recuperator to preheat the incoming sub cooled fluid before entering to economizer. Then it enters the condenser and is sub cooled entering the pump to raise its pressure to economizer pressure and cycle completes. The basic relations in an organic Rankine cycle is described here: [6]

Mass balance equation:

$\sum \dot{m}_{l}=\sum \dot{m}_{o}$

Energy balance equation:

$\dot{Q}-\dot{W}=\sum \dot{m}_{o} h_{o}-\sum \dot{m}_{l} h_{i}$

Steam generator (including Economizer, Evaporator and Super heater):

$\dot{Q}_{e}=\dot{m}_{i}\left(h_{i}-h_{o}\right)=U A_{E c o} \Delta T_{L M T D, E c o}+U A_{E v a} \Delta T_{L M T D, E v a}+U A_{\text {Sup }} \Delta T_{L M T D, S u p}$

Turbine isentropic efficiency:

$\eta_{\mathrm{T}}=\frac{\dot{W}_{T, a}}{\dot{W}_{T, s}}=\frac{h_{i}-h_{o, a}}{h_{i}-h_{o, s}}$

$\dot{W}_{T, a}=\sum \dot{m}_{l} h_{i}-\sum \dot{m}_{o} h_{o}$

Condenser:

$\dot{Q}_{\text {cond }}=\sum \dot{m}_{l} h_{i}-\sum \dot{m}_{o} h_{o}=U A_{\text {cond }} \Delta T_{L M T D}$

Pump isentropic efficiency:

$\eta_{\mathrm{P}}=\frac{\dot{W}_{p . s}}{\dot{W}_{p, a}}=\frac{v_{i}\left(P_{o}-P_{i}\right)}{h_{o}-h_{i}}$

Net output work of the system:

$\dot{W}_{n e t}=\dot{W}_{T, a}-\dot{W}_{p, a}$

Thermal efficiency of the system:

$\eta_{\mathrm{Th}}=\frac{\dot{W}_{\text {net }}}{\dot{Q}_{e}}$ 
In this study turbine isentropic efficiency and mechanical efficiency was supposed to be $80 \%$ and $99 \%$ respectively as a logical supposition [7]. A single stage refrigerant turbine was used because delivering small amounts of work up to $20 \mathrm{KWe}$ was considered [8]. The Recuperator model effectiveness was fixed to $80 \%$ corresponding to medium technology design [8] with a minimum pinch of $10^{\circ} \mathrm{C}$ and a maximum pressure drop of $3 \%$. Water-Cooled Condenser was used in the cycle with in and out water temperature $15^{\circ} \mathrm{C}$ and $25^{\circ} \mathrm{C}$ respectively, minimum pinch of $7^{\circ} \mathrm{C}$ was selected. An ORC pump with an $85 \%$ isentropic efficiency was selected [8]. The boiler consists of three heat exchangers, first of them to make the quality of vapor equal to zero $(x=0)$, second one to evaporate vapor to the saturated vapor in constant pressure $(x=1)$ and the other was used for superheating the vapor to some degree. For making comparison a fixed mass flow of $0.074 \mathrm{~kg} / \mathrm{s}$ was chosen for all working fluids in ORC cycle. For the sake of simplicity, the same system conditions described above was taken into account for all the working fluids.

\subsection{Working fluids}

Six fluids were chosen from Thermoflow [5] library, two refrigerants R123 and R245fa and four hydrocarbons Benzene, Iso-pentane, n-pentane and Butane to cover a wide range of working temperatures and pressures. Properties of these fluids are shown in table 1. One of the major concerns of organic fluids is their safety, global warming potential (GWP) relative to $\mathrm{CO}_{2}$, Ozone depletion potential (ODP) relative to R11 and atmospheric lifetime [9] which should be considered in fluid selection. Table 2 shows the ORC fluids min/max pressures and temperatures which were used in the modeling as the base case with the existence of Recuperator and Super heater.

Table 1. Working fluid properties [10, 11].

\begin{tabular}{|c|c|c|c|c|c|c|}
\hline Substance & \multicolumn{3}{|c|}{$\begin{array}{c}\text { Physical Data } \\
\mathrm{T}_{\mathrm{bp}}{ }^{\mathrm{a}}\left({ }^{\circ} \mathrm{C}\right) \mathrm{T}_{\mathrm{cr}}{ }^{\mathrm{b}}\left({ }^{\circ} \mathrm{C}\right) \\
\mathrm{P}_{\mathrm{cr}}{ }^{\mathrm{c}}(\mathrm{bar})\end{array}$} & $\begin{array}{c}\text { Molar mass } \\
(\mathrm{kg} / \mathrm{kmol})\end{array}$ & $\begin{array}{l}\text { Safety data } \\
\text { ASHRAE 34 } \\
\text { safety group }\end{array}$ & $\begin{array}{l}\text { Environmental Data } \\
\text { Atmospheric lifetime }^{\mathrm{d}} \\
\text { /GWP/ODP }\end{array}$ \\
\hline Benzene & 80.08 & 288.9 & 48.94 & 78.108 & - & - \\
\hline n-pentane & 36.06 & 196.55 & 33.70 & 72.149 & A3 & - \\
\hline R123 & 27.823 & 183.68 & 36.618 & 152.93 & B1 & $1.3 / 77 / 0.02$ \\
\hline Isopentane & 27.83 & 187.2 & 33.78 & 72.149 & A3 & $-/ 20 / 0$ \\
\hline R245fa & 15.14 & 154.01 & 36.51 & 134.05 & B1 & 7.6/1030/0 \\
\hline Butane & -0.49 & 151.98 & 37.96 & 58.122 & A3 & - \\
\hline
\end{tabular}

a: normal boiling point

b: critical temperature

c: critical pressure

$\mathrm{d}$ : Time in which the organic fluids remain in the atmosphere (year) 
Table 2. ORC fluids and their temperatures and pressures at turbine input and condenser output as the base case

\begin{tabular}{|c|c|c|c|c|}
\hline ORC fluid & $\mathrm{P}_{\mathrm{T}}($ bar $)$ & $\mathrm{T}_{\mathrm{T}}\left({ }^{\circ} \mathrm{C}\right)$ & $\mathrm{P}_{\mathrm{C}}($ bar $)$ & $\mathrm{T}_{\mathrm{C}}\left({ }^{\circ} \mathrm{C}\right)$ \\
\hline Benzene & 26.82 & 287 & 0.19 & 34.92 \\
\hline n-pentane & 25 & 190 & 1 & 35.72 \\
\hline R123 & 30 & 180 & 1.54 & 39.91 \\
\hline Isopentane & 30 & 185 & 1.28 & 34.76 \\
\hline R245fa & 22.61 & 150 & 2.14 & 35.04 \\
\hline Butane & 34.31 & 149 & 3.30 & 35.17 \\
\hline
\end{tabular}

\subsection{Collector model}

In this study, a parabolic trough solar collector was chosen as heat source. THERMINOL VP-1 was selected as the working fluid [12] and its characteristics are shown in table 3. Design point collector nominal optical efficiency of the collector was selected 0.82 according to equation (8) [4].

$\eta_{\text {opt }}=\rho_{\text {mirror }} \cdot \eta_{\text {shadowing }} \cdot \eta_{\text {geometry }} \cdot \eta_{\text {unaccounted }}$

Site latitude, altitude and hour of the day were considered 35 degrees, $1420 \mathrm{~m}$ and 12 respectively according to Tehran. Other input characteristics of solar collector are presented in Table 4.

Table 3. Thermal oil properties [12].

\begin{tabular}{|c|c|c|c|c|}
\hline Substance & $\begin{array}{c}\text { Min/Max temperature } \\
\left({ }^{\circ} \mathrm{C}\right)\end{array}$ & Density $\left(\mathrm{kg} / \mathrm{m}^{3}\right)$ & $\begin{array}{c}\text { Specific heat } \\
(\mathrm{kJ} / \mathrm{kg} . \mathrm{C})\end{array}$ & $\begin{array}{c}\text { Thermal } \\
\text { conductivity } \\
(\mathrm{w} / \mathrm{m} . \mathrm{C})\end{array}$ \\
\hline $\begin{array}{c}\text { THERMINOL VP- } \\
1\end{array}$ & $12.78 / 398.9$ & 1067.6 & 1.532 & 0.1368 \\
\hline
\end{tabular}


Table 4. Collector model parameters

\begin{tabular}{|c|c|}
\hline Parameter & Value \\
\hline$\rho_{\text {mirror }}$ & 0.94 \\
\hline$\eta_{\text {shadowing }}$ & 0.98 \\
\hline$\eta_{\text {geometry }}$ & 0.93 \\
\hline$\eta_{\text {unaccounted }}$ & 0.96 \\
\hline Receiver tube outer Diameter & $70 \mathrm{~mm}$ \\
\hline Reflector aperture width & $2.5 \mathrm{~m}$ \\
\hline Reflector row pitch/Aperture \\
width & 2.5 \\
\hline Reflector cleanliness factor & 0.95 \\
\hline Receiver tube emissivity & 0.14 \\
\hline Receiver glass envelope & 0.86 \\
\hline emissivity & $56.78 \mathrm{w} / \mathrm{m} 2^{\circ} \mathrm{C}$ \\
\hline $\begin{array}{c}\text { Convective heat transfer } \\
\text { coefficient outside glass envelope }\end{array}$ & $0.1 \mathrm{~kg} / \mathrm{s}$ \\
\hline \begin{tabular}{l} 
Mass flow rate of thermal oil \\
\hline
\end{tabular} & \\
\hline
\end{tabular}

\section{Results and discussion}

Table 5 summarizes the results for 6 working fluids with 4 schematics, simple Rankine cycle without Regenerator and Super heater, with superheating, with regenerating and with both of them. Results show that superheating could raise the system efficiency to some extent because the energy content of working fluid is raised but with superheating to high degrees it will cause decreased, unchanged or marginally improved cycle efficiency as can be seen in figure 3 for R245fa, Iso-pentane and butane and is based on reason that dry behavior of organic fluids causes the average temperature of heat rejection to increase together with the average temperature of heat addition [3]. So the net work out put does not increase sufficiently, but the amount of heat addition for superheating increases the heat input resulting to unchanged or decreased efficiencies but for some fluids such as Benzene and npentane and R123, we see an continuous increase in efficiency but there are some problems such as safety matters and cost which should be taken into account to choose working temperatures for fluids. This degree of superheating differs in each organic fluid and should be optimized for each one in different pressures and temperatures. Here we chose an acceptable temperature according to table 2 and optimized the cycle in term of pressure. Also table 5 shows that existence of Recuperator plays an important role in increasing efficiency, mainly because of dry behavior of organic fluids which their positive slope of T-S diagram causes the outlet state of turbine to be in superheated region so much energy could be recuperated from vapor to incoming fluid before entering to boiler by means of a 
Recuperator, because the output temperature of expander is much more than the output temperature of pump. Not only existence of Recuperator decreases the amount of heat addition to working fluids in heat exchangers, but also it decreases the condenser load to a great extent. Results of modeling different organic fluids are shown in table 5. Existence of both Recuperator an Super heater were investigated during modeling, results show that existence of both of them could be helpful and increase the cycle efficiency but amount of superheating should be chosen with care as mentioned above. So this schematic (figure 1) was chosen to study.

Table 5. Net electrical efficiency for different working fluids (percent)

\begin{tabular}{|l|l|l|l|l|}
\hline Working fluids & $\begin{array}{l}\text { Simple Rankine } \\
\text { cycle }\end{array}$ & $\begin{array}{l}\text { Addition of Super } \\
\text { heater }\end{array}$ & $\begin{array}{l}\text { Addition of } \\
\text { Recuperator }\end{array}$ & $\begin{array}{l}\text { Addition of Super } \\
\text { heater and } \\
\text { Recuperator }\end{array}$ \\
\hline Benzene & 20.14 & 20.38 & 22.08 & 24.17 \\
\hline n-pentane & 14.08 & 14.08 & 16.84 & 17.04 \\
\hline R123 & 12.89 & 13.16 & 13.61 & 16.26 \\
\hline Iso-pentane & 13.53 & 13.63 & 15.61 & 12.53 \\
\hline R245fa & 10.58 & 10.82 & 11.26 & 12.23 \\
\hline Butane & 11.34 & 11.51 & & 11.72 \\
\hline
\end{tabular}


Figure 3. Effect of superheating in different working fluids with Regenerator

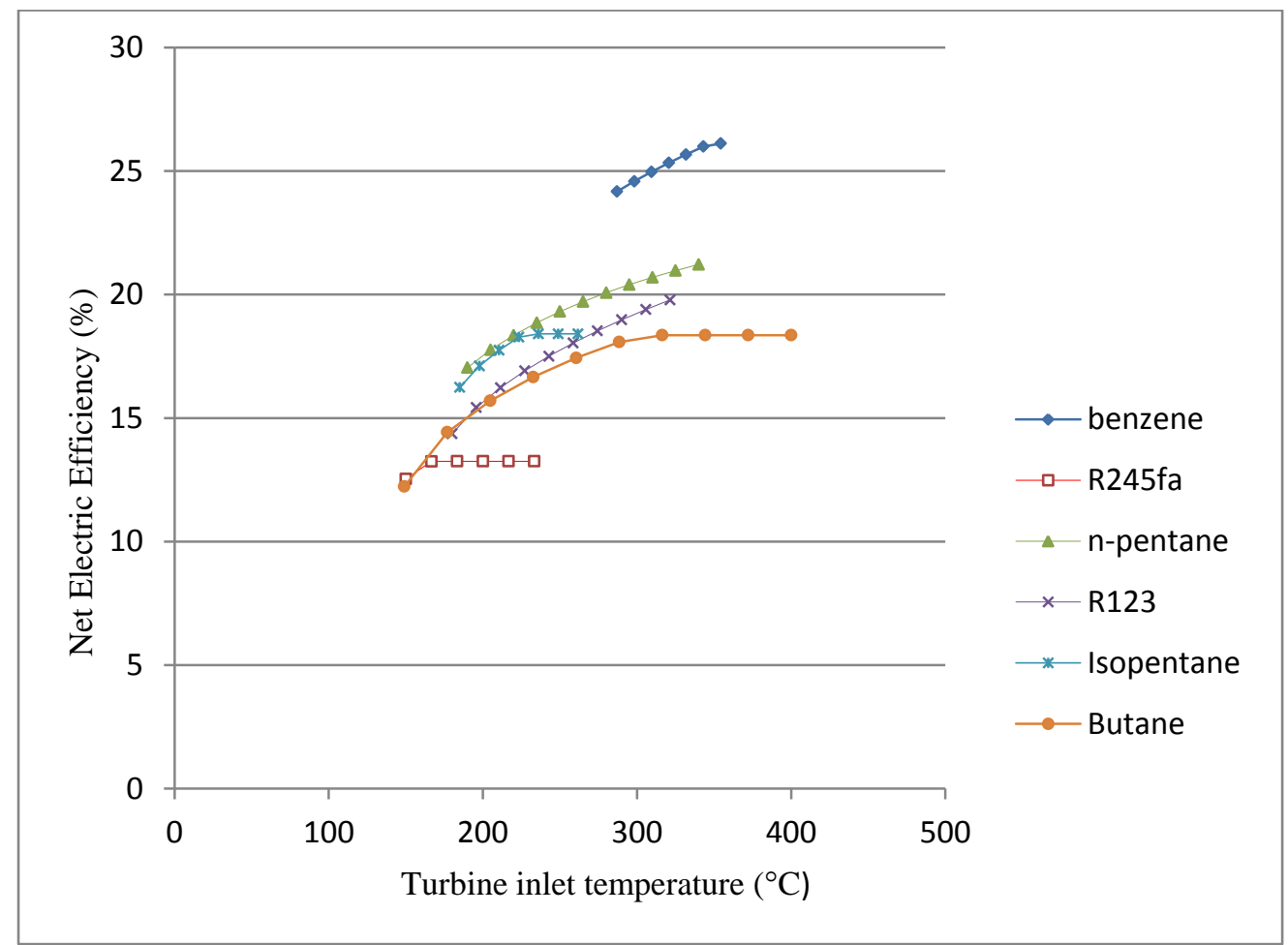

As can be seen in Table 5 among these 6 working fluids, Benzene shows the best performance for these conditions described. Here an analysis of ORC is done to find out the effect of various cycle parameters. Figure 4 and 5 show the effect of turbine inlet pressure on the efficiency and work output.

Figure 4. Effect of varying turbine inlet pressure on efficiency of the system

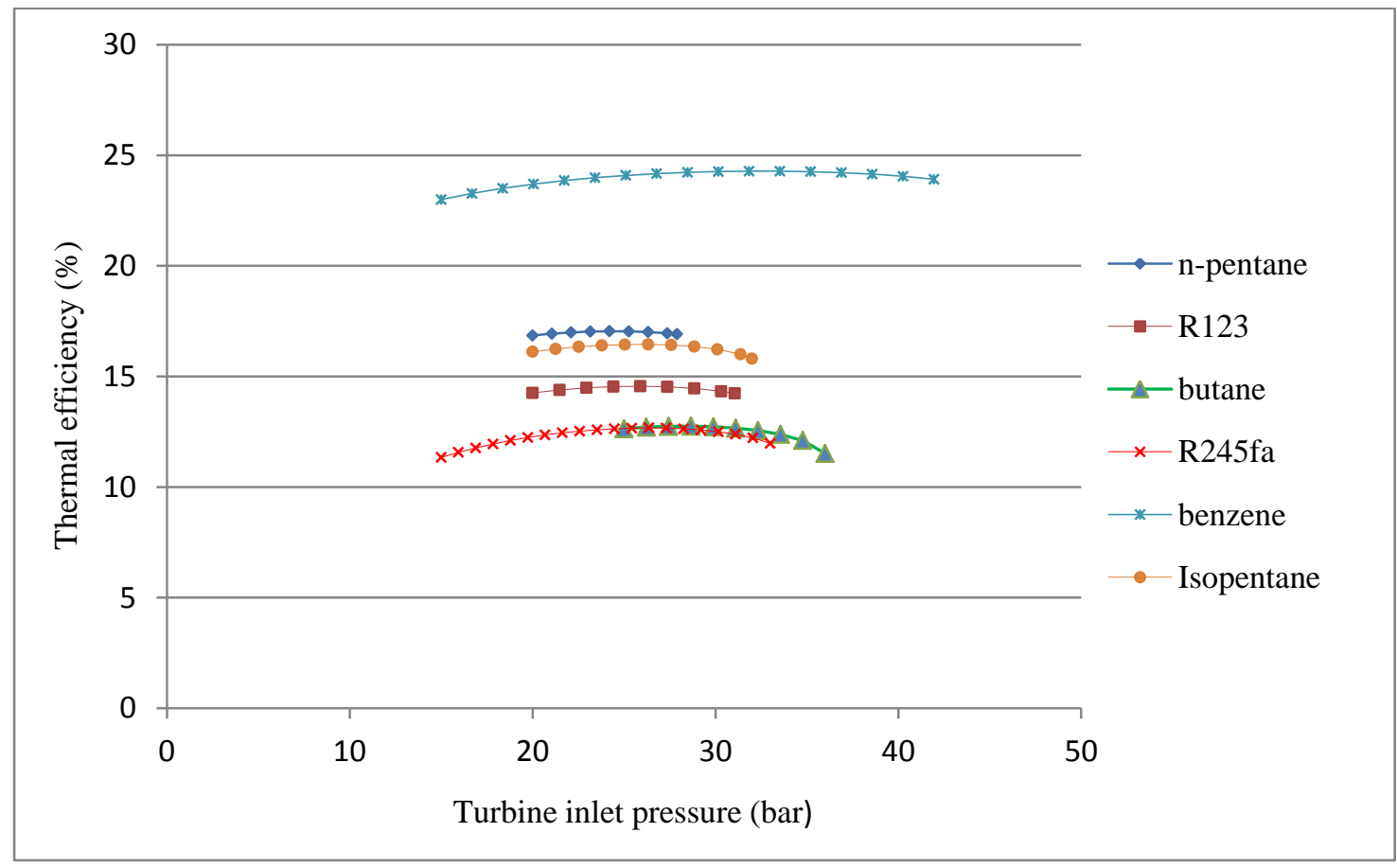


According to figure 4 there is an optimum pressure in each temperature for fluids, the reason for this behavior is lying in the h-s diagram of working fluids, when outlet pressure of turbine is fixed and input pressure rise, because of constant pressure curves the enthalpy difference between two pressures goes through a maximum [3]. This maximum for Benzene occurs at 31.84 bars.

Figure 5. Effect of Turbine inlet pressure on net output work

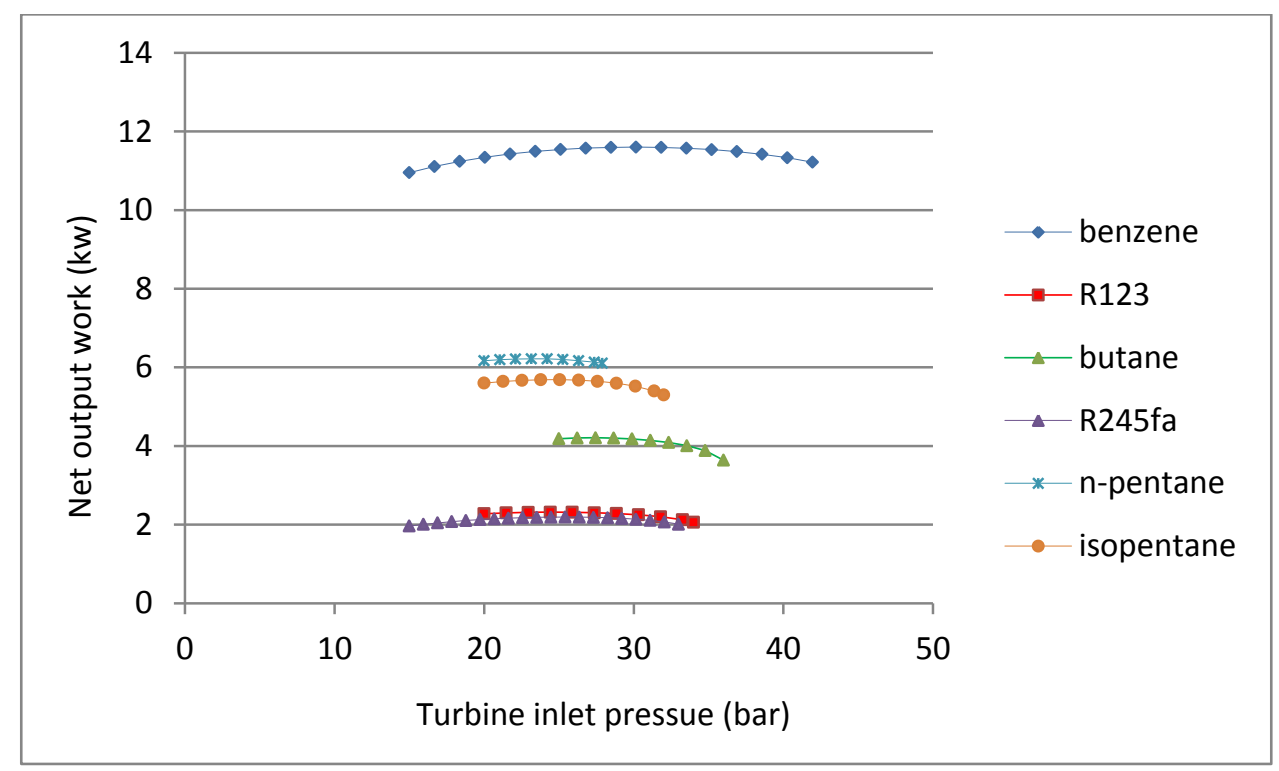

Figure 5 shows the effect of turbine inlet pressure on work output, the more pressure increases the more work produces but on the other hand the work consumed by pump to generate the required pressure also increases, also as mentioned above enthalpy difference across turbine goes through a maximum which plays a more important role in determining the net work output behavior, overall results are shown in figure 5. Also a noticeable interpretation from the figure 5 and 4 is that R123 produces less power than butane in all working pressures but has a more thermal efficiency in all pressures and this is because butane needs more heat to evaporate and reach the desired condition with the same mass flow rate. Optimized values for six working fluids in term of pressure in constant temperature are given in table 5.

Table 5. Optimized efficiencies in terms of input pressure for different fluids (\%)

\begin{tabular}{|l|l|l|l|l|l|l|}
\hline Working fluid & Benzene & n-pentane & Iso-pentane & R123 & Butane & R245fa \\
\hline Thermal efficiency & 24.28 & 17.04 & 16.45 & 14.55 & 12.75 & 12.67 \\
\hline
\end{tabular}

Figure 6 shows the effect of turbine inlet temperature on Thermal oil temperature difference $\left(\Delta T_{c o l}\right)$ in solar collector, increasing the temperature of working fluids causes the solar collector to increase the temperature difference in order for thermal oil to absorb more energy. This will lead to higher efficiency of collector which is shown on figure 7. 
Figure 6. Effect of turbine inlet temperature on thermal oil temperature

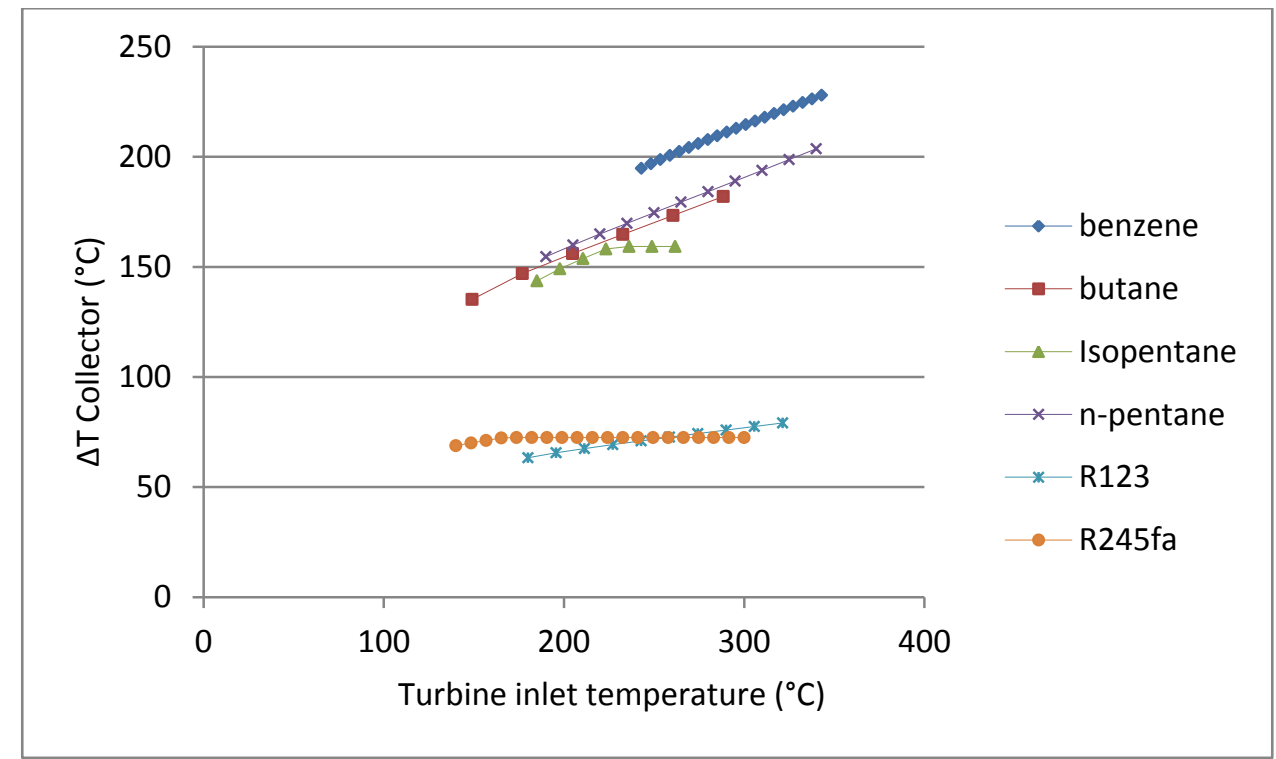

Figure 7. Effect of exit temperature of Superheater on collector efficiency

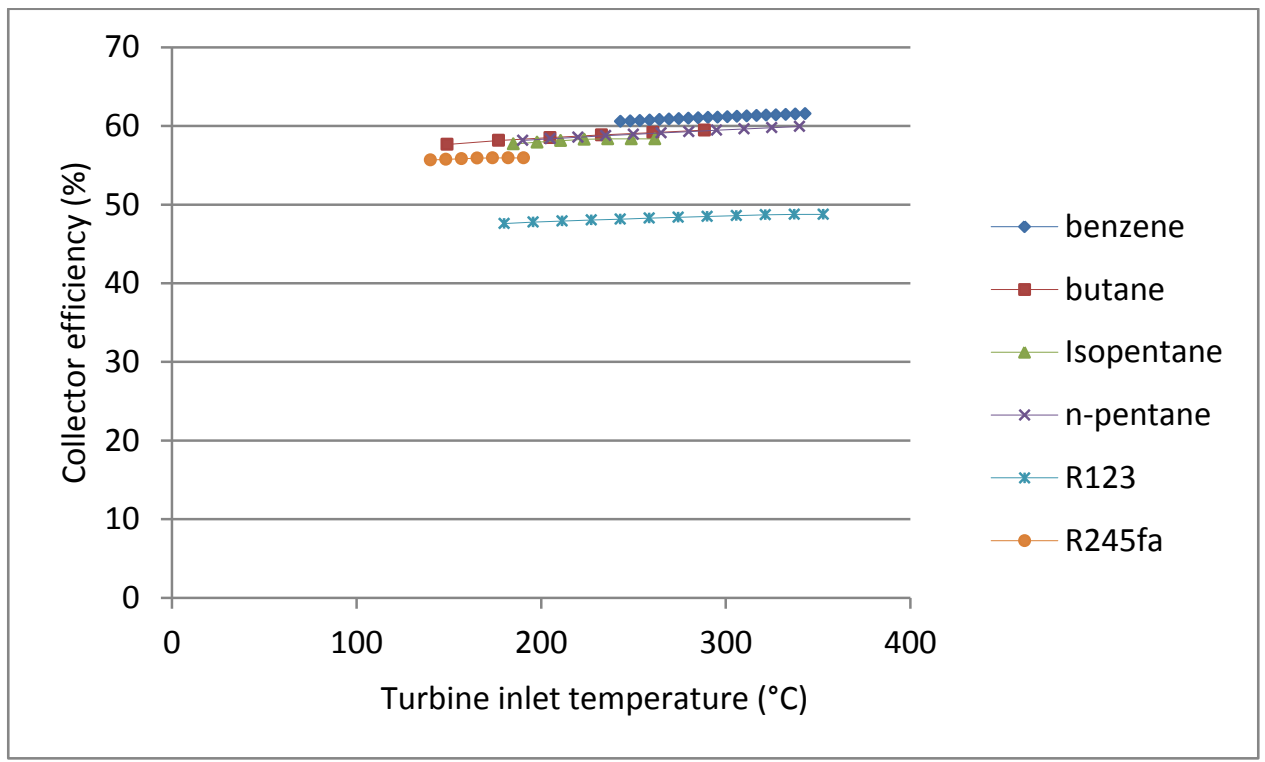

Figure 8 shows the multiplication of overall heat transfer coefficient and heat transfer area (UA) in three heat exchangers Economizer, Evaporator and Super-heater. When turbine input pressure increases with fixed outlet pressure, the amount of heat addition to Economizer also increases so as to make the sub cooled organic fluid to be saturated liquid which result in increased UA, on the other hand with rising pressure the enthalpy difference in two-phase area on the T-S diagram decreases leading to decreased amount of heat addition in evaporator also decreased UA. Also in the raised pressures, the same amount of superheating is obtained with less heat addition to organic fluid which causes another decreased UA in Super heater. Results show this effect for Benzene in figure 8. 
Figure 8. Effect of input pressure on characteristics of heat exchangers for Benzene

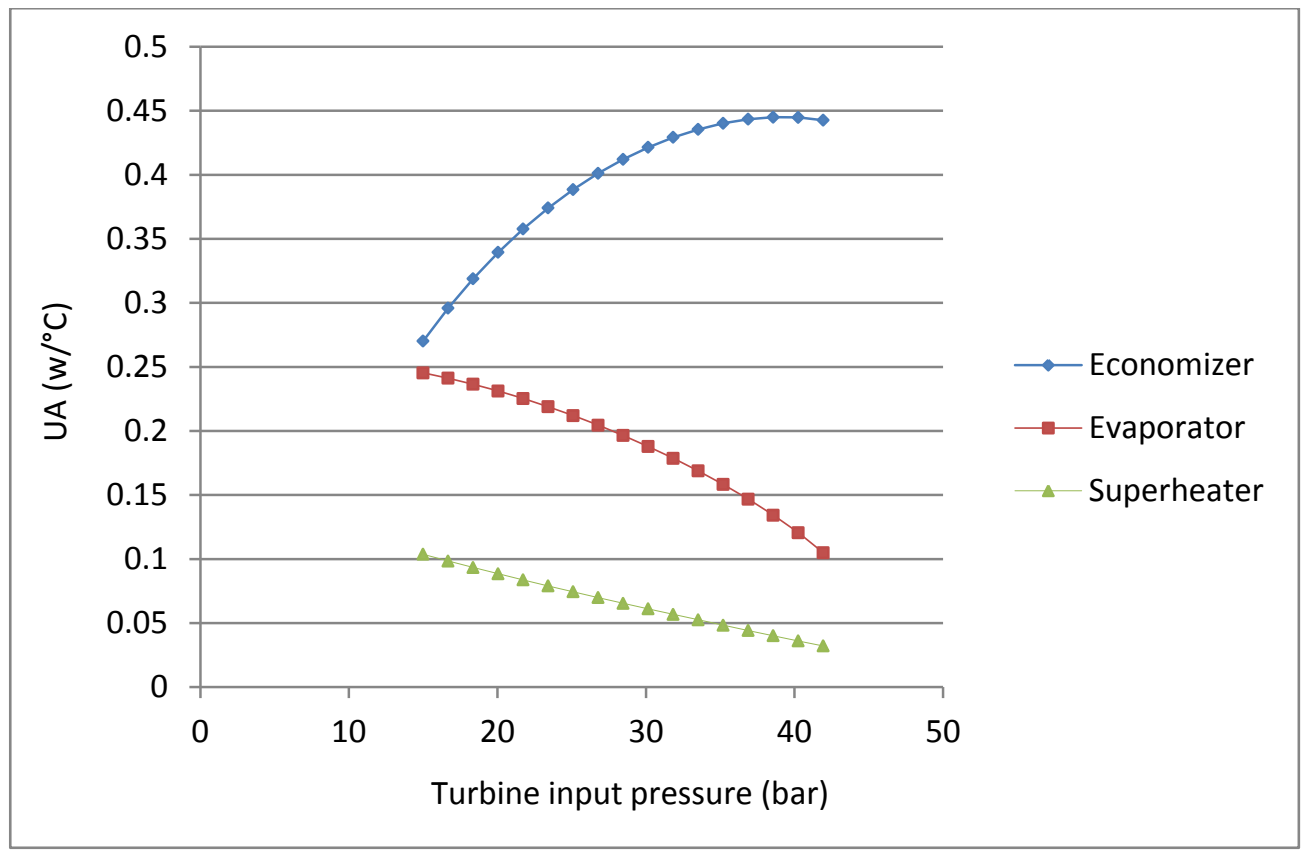

\section{Conclusions}

In this study an ORC engine coupled with parabolic trough solar collector was investigated in small scale suitable for distributed power generation. Six working fluids were examined in cycle with different working temperatures and pressures. Due to low mass flow rate of organic fluids a one stage scroll expander or piston expander could be a suitable choice which is commercially available. Three heat exchangers (Economizer, Evaporator and Super heater) were used as boiler, between solar collector and ORC engine. Effect of cycle characteristics such as turbine inlet pressure and temperature on cycle efficiency, power output, collector efficiency and current UA of heat exchangers were investigated. Cycle was optimized in term of pressure in constant temperature for maximizing thermal efficiency. Among these fluids, benzene shows the best performance in terms of efficiency (24.28\%) and followed by n-pentane, R123, Iso-pentane, Butane, R245fa. R245fa show an efficiency of $12.67 \%$ in the best condition mainly because of relative low temperature. THERMINOL VP-1 was used in collector as commercial widely used thermal oil and site specifications for solar collector were based on Tehran city. For large scale solar ORC engines a good choice would be double stage turbine with reheat and regeneration which could raise the cycle efficiency and power output. As shown on figure 3 raising the temperature of some organic fluids result in continuous improving efficiency but the main reason of relatively low efficiency of these organic fluids are the safety matters like flammability and explosion which finding a solution to that could raise the cycle efficiency and make organic Rankine cycle a reliable, high efficiency engine for distributed power generation.

\section{Nomenclature}

$\begin{array}{ll}A & \text { area }\left(\mathrm{m}^{2}\right) \\ \dot{m} & \text { mass flow rate }(\mathrm{kg} / \mathrm{s}) \\ h & \text { enthalpy }(\mathrm{kJ} / \mathrm{kg} \mathrm{K}) \\ \dot{Q} & \text { rate of heat transfer }(\mathrm{kW})\end{array}$




$\begin{array}{cl}\dot{W} & \text { power }(\mathrm{kW}) \\ U & \text { overall heat transfer coefficient }(\mathrm{W} / \mathrm{m} 2 \mathrm{~K}) \\ T & \text { Temperature } \\ \eta & \text { efficiency } \\ \text { Subscripts } & \\ \mathrm{i} & \text { inlet } \\ \text { o } & \text { outlet } \\ T & \text { turbine } \\ \text { LMTD } & \text { logarithmic mean temperature difference } \\ \text { cond } & \text { condenser } \\ E v a & \text { evaporator } \\ p & \text { pump }\end{array}$

\section{Conflict of Interest}

The authors declare no conflict of interest

\section{References and Notes}

1. Ferrara F, Gimelli A, Luongo A. Small-scaled concentrated solar power (CSP) plant: ORC's comparison for different organic fluids. Energy Procedia 45 (2014) 217-226.

2. Wang Jiangfeng, Zhequan Yan, Pan Zhao, Yiping Dai. Off-design performance analysis of a solarpowered organic Rankine cycle. Energy Conversion and Management 80 (2014) 150-157.

3. MCMAHAN ANDREW C. Design \& Optimization of Organic Rankine Cycle Solar-Thermal Powerplants. MSc Thesis, 2006.

4. Quoilin s, Orosz M, Hemond H, Lemort. Performance and design optimization of a low-cost solar organic Rankine cycle for remote power generation. Solar Energy 85 (2011) 955-966.

5. Therrmoflow Inc., 2009 , THERMOFLOW 19.0, Sudbury, MA.

6. El-Wakil MM. Power plant technology. McGraw-Hill; 2002.

7. Bianchi M, De Pascale A. Bottoming Cycles for Electric Energy Generation: Parametric Investigation of Available and Innovative Solutions for the Exploitation of Low and Medium Temperature13 Heat Sources. Applied Energy, 2011, 88, pp. 1500-1509.

8. Barbieri E, De Pascale A, Ferrari C, Melino F, Morini M, Pretto A, Pinelli M. Performance evaluation of the of the integration between a Thermo-Photo-Voltaic Generator and an Organic Rankine Cycle. Journal of Engineering for Gas Turbines and Power, October 2012, Vol. 134/ 102301-1.

9. Tchanche Bertrand Fankam, Papadakis George, Lambrinos Gregory, Frangoudakis Antonios.

Fluid selection for a low-temperature solar organic Rankine cycle. Appl Therm Eng 2009; 29(11- 12): 2468-76

10. ASHRAE (2009) Handbook Fundamentals, Chapter 29, Refrigerants.

11. Lemmon E. W., McLinden M. O., and Huber, M.L., 2007, NIST Standard Reference Database 23: Refrence Fluid Thermodynamic and Transport Properties-REFPROP, Version 8.0, National Institute of Standard and Technology. Gaithersburg, MD. 
12. Therminol Heat Transfer Fluids by Solutia Inc. Therminol VP 1,http://www.therminol.com/pages/products/vp-1.asp; 2012.

(C) 2014 by the authors; licensee MDPI, Basel, Switzerland. This article is an open access article distributed under the terms and conditions of the Creative Commons Attribution license. 